\title{
Construcciones altomedievales en materiales perecederos en el yacimiento de Revenga (Burgos): algunas reflexiones para su interpretación arqueológica
}

\section{Early Medieval structures in perishable building materials at the site of Revenga (Burgos): some thoughts for their archaeological interpretation}

\author{
Karen Álvaro Rueda ${ }^{1}$, Esther Travé Allepuz ${ }^{2}$, M. a Dolores López Pérez ${ }^{3}$ \\ Universidad de Barcelona
}

\begin{abstract}
RESUMEN
Las recientes intervenciones en el yacimiento de Revenga (Comunero de Revenga, Burgos) han dado a conocer una secuencia de habitación marcada por la ocupación continuada del espacio y una intensa reutilización de estructuras, a la par que el poblado experimenta distintas transformaciones en su ordenación interna entre los siglos V-IX. La interpretación arqueológica de un hábitat del que quedan en realidad muy pocos restos, dado el carácter perecedero de sus construcciones, es especialmente compleja. En este trabajo se analizan algunos ejemplos de estructuras excavadas en el yacimiento de Revenga que presentan procesos de reconstrucción o reocupación del espacio con el fin de plantear algunas reflexiones acerca de los problemas interpretativos que de ellas se derivan y contribuir al estudio del poblamiento altomedieval mediante la construcción de un registro arqueológico de calidad.
\end{abstract}

Palabras clave: estructuras rupestres; reconstrucción; reutilización; hábitat altomedieval.

\begin{abstract}
Recent works at the archaeological site of Revenga (Comunero de Revenga, Burgos) revealed a stratigraphic sequence featured by the uninterrupted occupation of space and intense reuse of structures. This correlates with the settlement transformation and the changes occurred within its internal structure between $5^{\text {th }}-9^{\text {th }}$ Centuries. The archaeological interpretation of habitat remains is a complex issue, due to the perishable character of building materials used. Within this piece of research, several structures discovered at Revenga exhibiting rebuilding or reuse processes are analysed in order to discuss some matters related to their interpretative problems. Our contribution aims at offering a better insight of medieval settlements and at building a high quality archaeological register.
\end{abstract}

Key words: rock-cut structures; rebuilding; reuse; early medieval habitat.

Recibido: 28-07-2017. Aceptado: 19-09-2017. Publicado online: 18-07-2018

Cómo citar este artículo / Citation

Álvaro Rueda, K., Travé Allepuz, E. y López Pérez, M.a D. 2018: "Construcciones altomedievales en materiales perecederos en el yacimiento de Revenga (Burgos): algunas reflexiones para su interpretación arqueológica", Arqueología de la Arquitectura, 15: e070. https://doi.org/10.3989/ arq.arqt. 2018.005

Copyright: (c) 2018 CSIC. Este es un artículo de acceso abierto distribuido bajo los términos de la licencia de uso y distribución Creative Commons Reconocimiento 4.0 Internacional (CC BY 4.0). 


\section{INTRODUCCIÓN}

Las excavaciones arqueológicas llevadas a cabo en el yacimiento de Revenga (Comunero de Revenga, Burgos) en los últimos años han puesto al descubierto un conjunto numeroso de estructuras de hábitat altomedieval. Este poblamiento, articulado en cuatro fases sucesivas, se caracteriza por la marcada continuidad de una ocupación que parece iniciarse entre los siglos V y VI y se extiende de manera ininterrumpida hasta el siglo XIII, cuando se integra junto con otros lugares de la zona en el dominio abacial de San Pedro de Arlanza (Escalona 2002: 174).

Resulta francamente imposible analizar este yacimiento sin vincularlo con su entorno más inmediato, puesto que Revenga constituye un asentamiento integrante de una red aldeana más amplia que puebla un entorno montañoso, el de la Alta Sierra, entre las cabeceras de los ríos Arlanza y Duero (Fig. 1). Este corredor situado entre los 1000 y 1200 m de altitud, en las estribaciones inferiores de la Sierra de la Demanda y los Picos de Urbión, presenta una densidad notable de asentamientos, conocidos especialmente por sus necrópolis rupestres de sepulturas antropomorfas. En todos ellos podemos observar un número variable de tumbas excavadas en la roca que presentan una disposición más o menos ordenada en torno a un centro de culto de reducidas dimensiones.

El conjunto de asentamientos serranos del Alto Arlanza se distribuye en este espacio montañoso de manera aglomerada pero no compacta y presenta una cierta jerarquización interna, con centros de mayor o menor preeminencia, a juzgar por las dimensiones heterogéneas de los cementerios que, por ahora, identifican a la mayoría de ellos. El análisis tradicionalmente focalizado en el estudio del espacio funerario ha relegado a un segundo plano los vestigios del poblamiento que necesariamente se relacionaba con estos asentamientos. La presencia de agujeros de poste, encajes, pequeñas zanjas y otras evidencias de ocupaciones domésticas suponen indicios claros de la existencia de estructuras de habitación. Poco más podemos saber, a priori, de estos espacios de hábitat si se limita su estudio a una mera prospección en superficie.

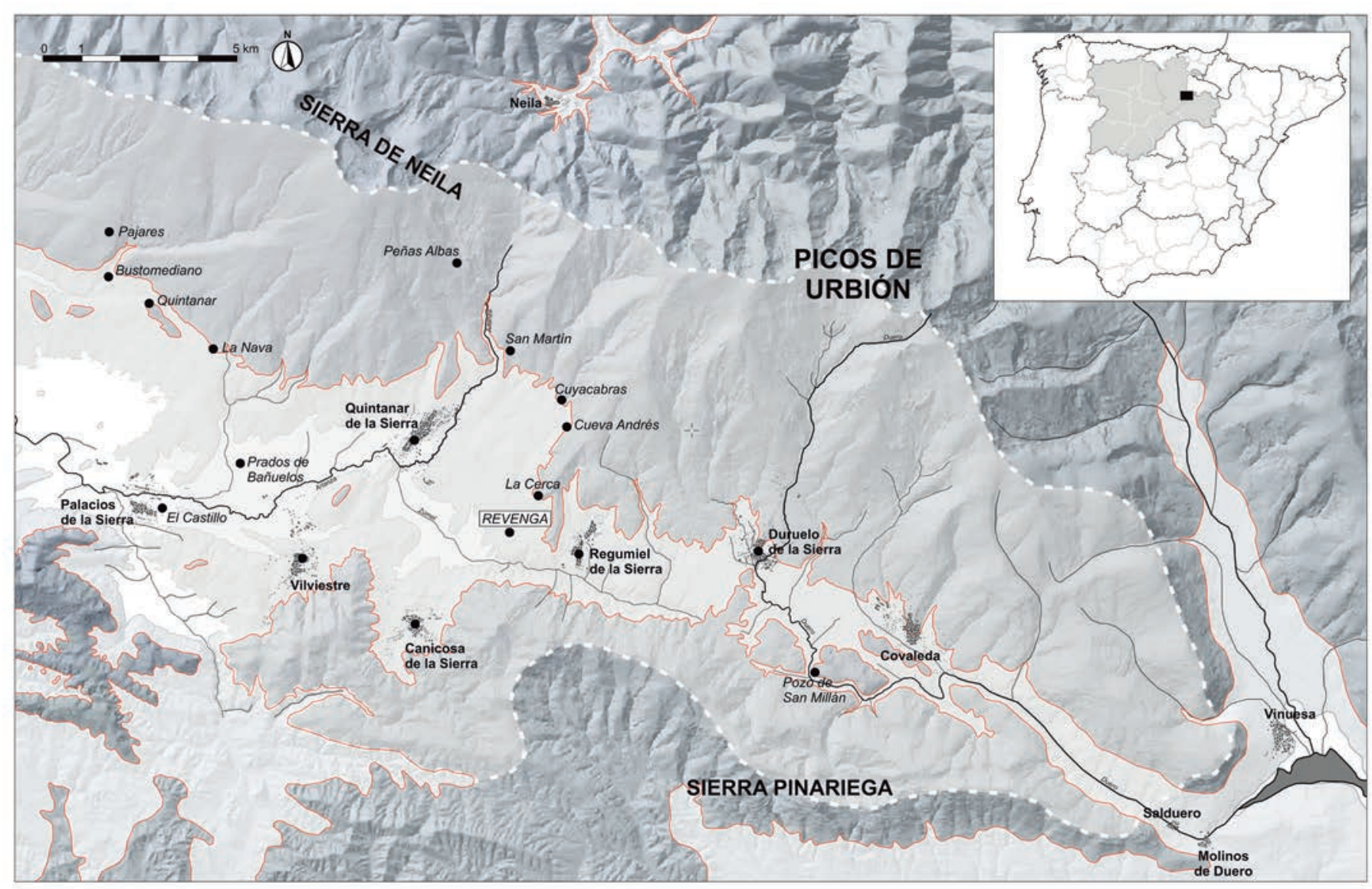

Figura 1. Mapa de localización de los asentamientos del Alto Arlanza y del espacio que denominamos Alta Sierra, que conforma el área periférica que es objeto de nuestro análisis. 
Sólo a partir de la excavación arqueológica de estos enclaves se puede superar la visión parcial y fragmentaria de los asentamientos, que asocia las necrópolis y lugares de culto a unos espacios de vivienda que en la mayoría de casos se intuyen pero no se conocen (Padilla y Álvaro 2010: 279). Así pues, el trabajo de prospección deviene imprescindible para localizar y acotar la extensión teórica del poblamiento, pero no revela mucho más acerca de su morfología y características. Para abordar el estudio de los rasgos arqueológicos de esta red aldeana necesariamente debe construirse un registro arqueológico adecuado a partir de una excavación en extensión a fin de que, como se reclama frecuentemente, se puedan proporcionar plantas integrales comprensibles que permitan crear una masa crítica de estudio de una cierta entidad (Quirós 2011: 78; Padilla y Álvaro 2013: 37).
En la actualidad estamos en condiciones de ofrecer este registro para el asentamiento de Revenga e interpretar algunas de sus características. Los restos arqueológicos de que disponemos se corresponden con fondos de cabaña de dimensiones y rasgos variables que reflejan una secuencia continuada de ocupación marcada por un momento de profunda reestructuración del poblado. Para este trabajo hemos seleccionado cuatro puntos concretos del yacimiento en donde se advierte con claridad una superposición de estructuras (Fig. 2) con estratigrafía asociada que atestiguan un proceso de ocupación, transformación y reestructuración del espacio, ya se trate de una sucesión de fases claramente diferenciadas y generalizables al conjunto del asentamiento o bien de momentos puntuales de reconstrucción y reutilización de habitáculos durante un mismo periodo.

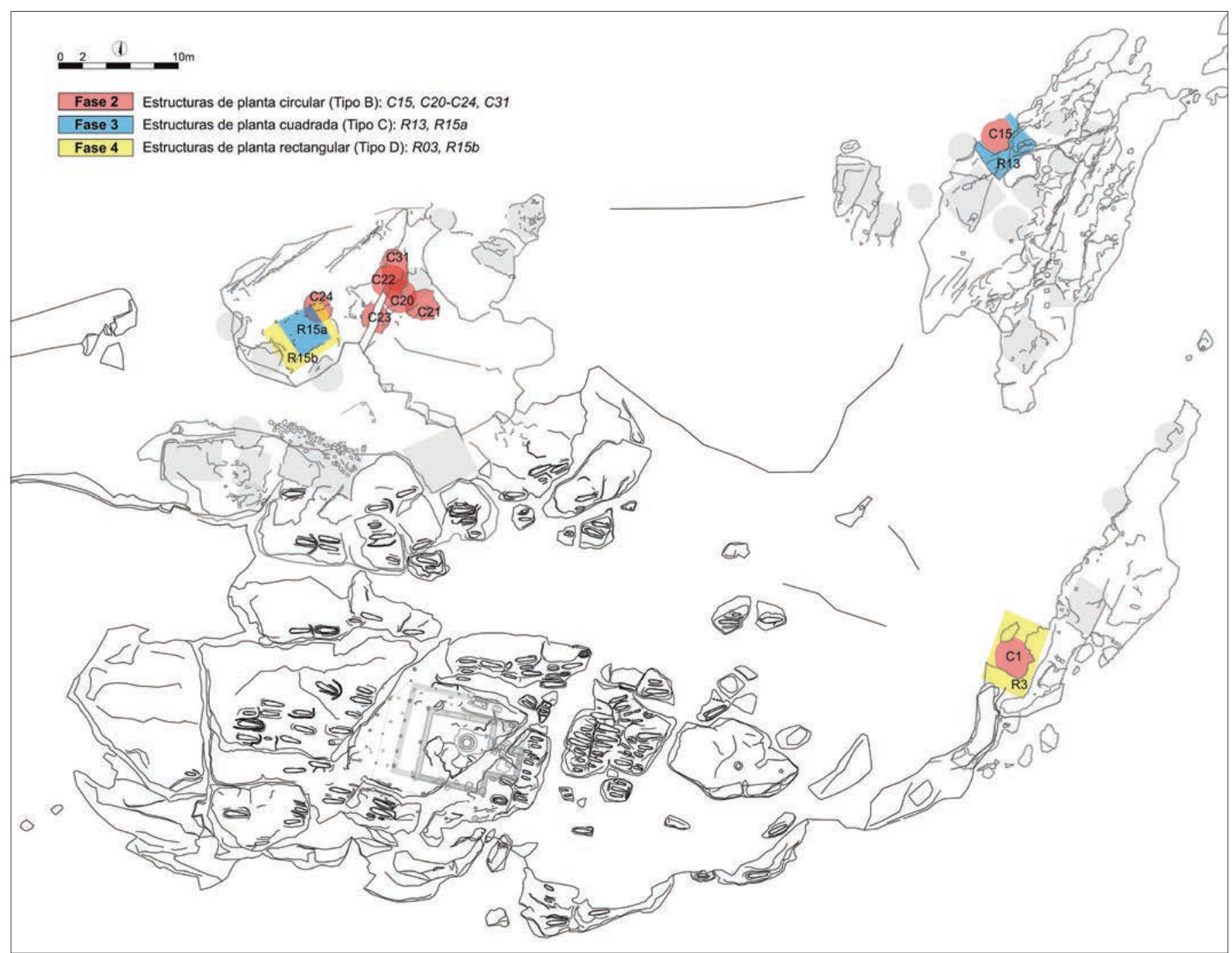

Figura 2. Planta general del yacimiento de Revenga, con detalles de la superficie rocosa excavada y de las estructuras identificadas. En ella se muestra la selección de espacios en los que se detecta una superposición clara de elementos en base a la estratigrafía recuperada. 
El análisis de estas evidencias sirve como hilo conductor para plantear algunos problemas interpretativos que parecen comunes a la mayoría de asentamientos rurales, pero que necesariamente deben analizarse en clave microregional. Un conjunto muy nutrido de excavaciones realizadas hasta hoy ha dado a conocer los rasgos principales del poblamiento rural en un periodo de transición entre las formas bajoimperiales de gestión del territorio y una nueva configuración del paisaje que cristaliza a lo largo del periodo feudal. Sin embargo, el estudio de estos procesos es complejo, en particular cuando analizamos el periodo de transición entre una y otra realidad, porque las fuentes escritas son prácticamente inexistentes y las arqueológicas muy escasas y, cuando tenemos ocasión de hallarlas, ni unas ni otras son sencillas de interpretar y aún menos de relacionar.

Por ello, conviene no sólo incrementar el volumen de los yacimientos conocidos y la calidad del registro sino también ser capaces de cambiar el enfoque en la manera de aproximarnos a este tipo de evidencias (Padilla y Álvaro 2010: 264-265), que exigen un trabajo de relectura permanente, tanto en su faceta material como documental, es decir, de hacer un esfuerzo por interpretar de manera conjunta ambas fuentes de información (Kirchner 2010: 246). Una tarea fundamental, en el caso de Revenga, ha sido la revisión profunda y permanente de la documentación antigua generada a la luz de los nuevos hallazgos. Esta revisión de un registro topográfico especialmente minucioso del suelo rocoso y del abundante material fotográfico obtenido a partir de los trabajos de prospección no intrusiva en el yacimiento permite advertir rasgos propios del hábitat que pueden permanecer inadvertidos antes de llevar a cabo la excavación (Fig. 3). Poner todos estos elementos sobre la mesa a fin de comprender el yacimiento de Revenga como un espacio vivo que aglutina un centro de culto, una necrópolis rupestre y un entorno habitado y precisar las características del mismo es nuestra tarea fundamental a lo largo de estos años.
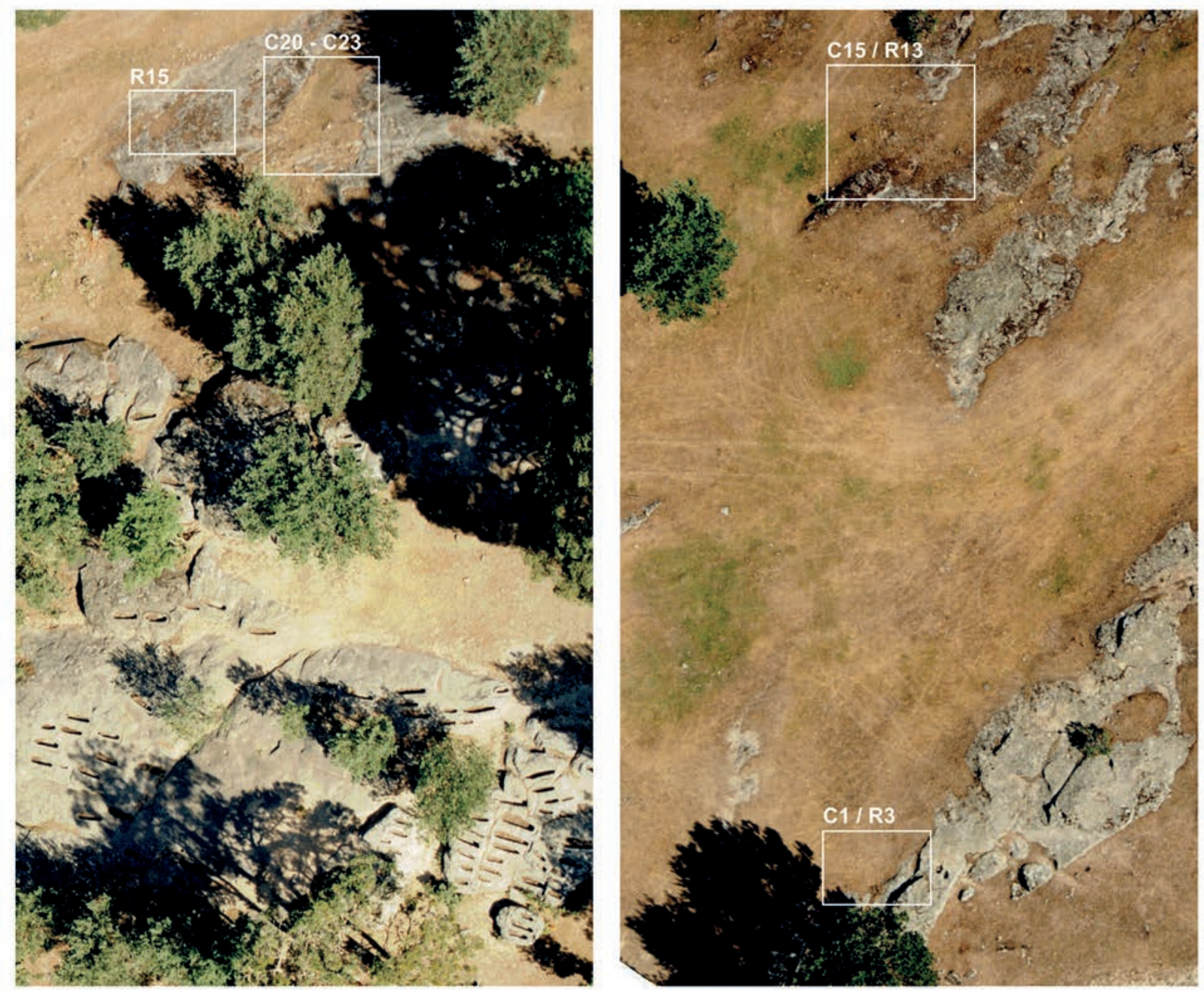

Figura 3. Fotografías aéreas realizadas a finales de los noventa sobrevolando el yacimiento en globo aerostático. En la actualidad, la presencia cada vez más frecuente de drones en los yacimientos arqueológicos facilita la obtención diaria de fotografías aéreas. 


\section{PRECISIONES METODOLÓGICAS E INTERPRETATIVAS DE LA SECUENCIA DE OCUPACIÓN}

A grandes rasgos, el periodo comprendido entre los siglos IV-VIII refleja el proceso de declive del Imperio Romano y sus consecuencias que, en función de la incidencia de las diversas formas de asentamiento sobre los territorios peninsulares, puede explicarse en base a distintos fenómenos: el final de las villae; la transformación de los espacios urbanos, es decir, la crisis de las ciudades romanas en tanto que elementos articuladores del territorio; la ocupación de los asentamientos fortificados en altura y la aparición de las primeras comunidades campesinas (Tejerizo 2016: 383).

Estos factores, especialmente elocuentes en las áreas que experimentaron un proceso de romanización más evidente, no permiten explicar el origen de la red aldeana en la totalidad del territorio, entendiendo esta red como un conjunto de enclaves articulados entre ellos con una cierta jerarquía espacial (Padilla y Álvaro 2010: 281). Existen otros polos de agregación o concentración del poblamiento al margen de la desestructuración de las villae, que no siempre podemos relacionar con una acción de los grupos dominantes (Schneider 2007), ni con el cambio de usos de las villae, su posterior abandono o su reocupación en momentos aún más tardíos (Tejerizo 2016: 390). Resulta imprescindible tener en cuenta que el análisis de un proceso de transición necesariamente debe tener en cuenta las formas anteriores de ocupación y su evolución diferenciada debido a los particularismos regionales que matizan en buena medida las formas de implantación romana (Gutiérrez 1998: 177). En base a este planteamiento, se pueden analizar las transformaciones del poblamiento en el territorio astur, en donde unas bases castreñas de origen prerromano con unas élites integradas en los sistemas de poder central condicionaran también el poblamiento altomedieval (Gutiérrez 1998: 181), por ejemplo.

Revenga, sin embargo, presenta los rasgos particulares que le confiere el carácter periférico de la zona (Padilla y Álvaro 2010: 275), marcado por las condiciones climáticas y orográficas propias de un espacio de montaña. El carácter aislado de estos enclaves y la ausencia en el registro arqueológico de una cultura material de base romana - carecemos de producciones cerámicas tardorromanas o de imitación de cualquier tipo- - parece abogar por la existencia de unas comunidades que viven al margen de una superestructura política que articule el territorio en base a las necesidades e intereses de un poder establecido. En la Alta Sierra en donde nacen el Arlanza y el Duero, no apreciamos poblamiento romano en la cota de $1200 \mathrm{~m}$, ni ningún otro elemento que nos permita asumir la presencia de un control efectivo por parte de las autoridades bajoimperiales. Las evidencias de ocupación romana más cercanas las encontramos en las localidades vecinas de Palacios de la Sierra y Vinuesa (Padilla y Álvaro 2010: 286), ambas por debajo de la cota de los $1100 \mathrm{~m}$. Los asentamientos situados por encima de este límite orográfico, en su mayoría alrededor de los $1200 \mathrm{~m}$ de altitud, parecen estar organizados con un cierto carácter autónomo al menos en su origen.

A tenor del registro arqueológico disponible, el poblamiento detectado en Revenga, no parece en ningún caso anterior a los siglos IV-V, ni tampoco se vincula a ningún enclave que pueda atribuirse con seguridad al periodo prerromano. Se trata de un contingente de población cuyo origen aún desconocemos y que parece vivir al margen de las estructuras de poder a las que no se integra hasta el siglo XI, cuando el territorio pasa a formar parte del Alfoz de Lara (Escalona 2002). En efecto, la información arqueológica recuperada hasta hoy nos pone en condiciones de afirmar que el asentamiento de Revenga estaba ya habitado alrededor de los siglos V-VII y que, por lo tanto, existen unos precedentes tardoantiguos - que no romanos ni prerromanos- en la formación del poblado, cuyo origen se había vinculado a la formación de la necrópolis, atribuida a los siglos VIII-IX (Padilla y Álvaro 2011a: 69).

Aun así, este poblamiento temprano experimenta una profunda reestructuración que estimamos alrededor del siglo VIII (Wickham 2013: 243) y que conlleva una transformación de la apariencia del enclave, cuando se documenta una sustitución de unas estructuras de planta preferentemente circular y dimensiones relativamente reducidas por otras de plantas cuadrangulares y de tamaño algo superior. El poblado está presidido por una iglesia en la que se detectan al menos dos fases de construcción. Los rasgos y estructura de la misma han sido ampliamente analizados y publicados en trabajos anteriores (Álvaro y Padilla 2012: 450-452), por lo que no redundaremos en su descripción. La necesaria revisión del registro arqueológico nos ha llevado a realizar un análisis pormenorizado de las trazas de talla existentes en promontorio rocoso sobre el que se asienta el edificio de culto. Dicho análisis nos permite advertir indicios de la presencia de estructuras circulares profundamente afectadas por la construcción de la necrópolis posterior, 
mientras que las fases de planta cuadrada aparecen ordenadas alrededor de dicho promontorio sin invadir el recinto sacro formado por la iglesia y su cementerio circundante. Esto nos lleva a pensar que la transformación sustancial del poblado que cambia el aspecto general y organización del mismo debería vincularse al proceso de cristianización de la Alta Sierra que dará lugar al origen de las necrópolis rupestres y que quizás se podría explicar a partir de la llegada de algún contingente poblacional foráneo, a priori relacionable con el área de la Rioja, a través del paso de Neila (Padilla y Álvaro 2010: 294).

La existencia de un asentamiento anterior a lo tradicionalmente asumido queda avalada por las más de cincuenta estructuras halladas en Revenga, que responden a una morfología variada entre la que distinguimos una serie de fondos de cabaña circulares de dimensiones reducidas y fondo rehundido (tipo A); un segundo grupo también de planta circular pero de tamaño mayor, que constituye el conjunto más numeroso detectado en el área excavada hasta ahora (tipo B); unas estructuras medianas de planta cuadrada (tipo C) y unas estructuras de planta rectangular y grandes dimensiones (tipo D). A ello se añaden dos estructuras claramente diferenciadas de dimensiones excepcionales, una de las cuales - ya identificada y documentada desde los primeros trabajos realizados en el lugar - es la que corresponde al centro de culto del asentamiento (Fig. 4).

El análisis de estas estructuras no está exento de problemas ya que desde una óptica meramente terminológica las posibilidades de nombrar este tipo de evidencias se revelan también variopintas. No nos desagrada el término genérico fondos de cabaña, puesto que en ningún caso disponemos de evidencias arqueológicas que se levanten siquiera un palmo del nivel del suelo. Si dejamos de lado las huellas de la iglesia que preside el promontorio (Padilla y Álvaro 2011a: 71-75), las estructuras identificadas y que son objeto principal de este trabajo corresponden en su mayoría con lo que tradicionalmente se ha identificado como fondos de cabaña, empleando un término generalmente aceptado en lengua castellana, muy extendido e importado del francés fond de cabanne (Chapelot 1980). En cualquier caso, somos conscientes de la imprecisión del término cabaña en contextos altomedievales, y del debate que suscita dadas las connotaciones de ruralidad, pobreza, tosquedad, marginalidad y provisionalidad del mismo, así como las implicaciones de dicho vocablo en relación con la presunción de funcionalidad al margen de la caracterización arqueológica y formal (Azkárate y Quirós 2001: 28).
A fin de evitar estos problemas interpretativos, en trabajos recientes C. Tejerizo $(2014,2016)$ propone seguir la terminología anglosajona propuesta por P. Rahtz (1976: 70-73; West 1986) según la cual se identifican como sunken-featured buildings (SFB) estas estructuras domésticas cuyo elemento estructural más destacado, en términos de registro arqueológico, es una fosa excavada en el terreno natural, más o menos regularizada y de fondo allanado y cuya morfología se caracteriza por ser más extensa que profunda y más o menos regular en torno a formatos ovalados o cuadrangulares, sobre la que se levantaría la estructura edilicia, generalmente de materiales perecederos; refiriéndonos pues a ellas en castellano como estructuras de fondo rehundido (EFR) (Tejerizo 2014: 217). Este tipo de estructuras fueron claramente identificadas y tipificadas en la arqueología medieval británica incluso antes de la acuñación del término como tal refiriéndose a ellas como pit-houses o sunken-floor huts basándose en la terminología alemana que las denomina grubenhaüser (West 1969: 4; Addyman y Leigh 1973: 7 y ss.). El concepto define pues una tipología clara, claramente identificada como tal y con un vasto repertorio bibliográfico al respecto (Gardiner 2012: 232, Fig. 1, 244-246).

La dificultad, en nuestro caso, radica en el hecho de que el conjunto de estructuras identificadas en Revenga no siempre coincide con dicha definición, sino que también hallamos —aunque en un número significativamente menor - estructuras cuya planta tallada sobre el suelo rocoso no aparece rehundida sino realzada, es decir, que se documenta un pequeño zócalo de piedra que aparece en ligero relieve sobre la cota media del suelo. Este tipo de estructura parece diferir de lo que A. Vigil-Escalera denomina construcciones "en superficie" (Vigil-Escalera 2003: 288) —también presentes en Revenga- - y que, según el autor, nos muestran edificaciones provistas de zócalos de piedra sin concertar ni apenas desbastar, alzados preferentemente en tapial y cubiertas de teja curva. Los zócalos casi no presentan zanja de cimentación, o lo hacen de forma muy somera, y no se advierte el uso de morteros ni la existencia de pavimentos que no sean de tierra apisonada o el propio firme geológico regularizado. En este caso concreto, sin embargo, nos referimos al propio suelo rocoso que constituye dicho zócalo mediante el rebaje de la superficie exterior de la estructura, sin que necesariamente se haya recuperado la construcción en superficie.

Dada esta variabilidad tipológica, hemos optado por referirnos al conjunto empleando el término genérico de estructuras de hábitat o de culto, siendo conscientes que 


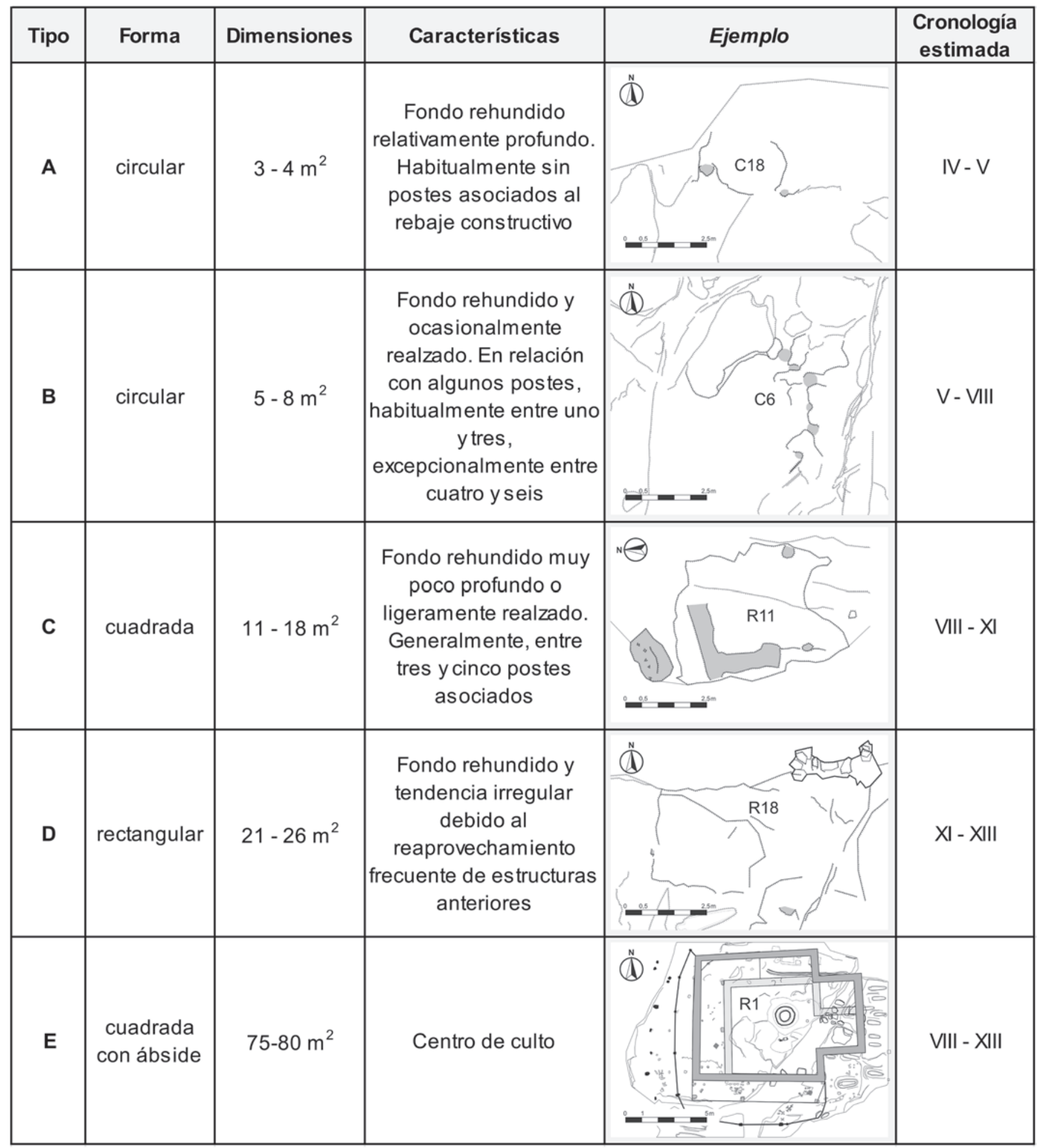

Figura 4. Tabla de clasificación tipológica de las estructuras de hábitat y de culto excavadas en Revenga, con indicación de sus rasgos principales y cronología estimada. 
estamos interpretando una funcionalidad de dichas estructuras, y analizar la morfología precisa en cada caso. Cabe destacar, de hecho, que los espacios en los que se ha interpretado la existencia de una actividad productiva de cualquier tipo - que también los tenemos en Revenga - no aparecen directamente relacionados con estos elementos sino que se trata más bien de ubicaciones al aire libre, por lo que no parece descabellado a priori relacionar las estructuras descritas (rehundidas o no) con usos domésticos. Por todo ello y de manera genérica, la denominación tradicional de los fondos de cabaña, aunque problemática en ocasiones como ya se ha hecho notar, no ha sido totalmente eliminada de nuestro vocabulario puesto que en determinados casos las estructuras detectadas son interpretables como cabañas en el sentido literal del término, con sus matices y connotaciones.

Las variantes tipológicas anteriormente mencionadas (Fig. 4) se relacionan con las distintas fases de evolución del asentamiento, en base a la secuencia estratigráfica recuperada (Fig. 5). Las cabañas circulares de tipo A parecen corresponder al momento de ocupación más antiguo. Los escasos ejemplares recuperados aparecen muy arrasados y en ocasiones desdibujados por intensos trabajos de labra posteriores sobre el suelo rocoso. Poca más información podemos proporcionar al respecto y las incógnitas acerca de estas primeras formas de ocupación del asentamiento todavía son numerosas. El carácter aislado de estas cabañuelas circulares se contrapone a las estructuras del tipo B, que aparecen concentradas en áreas concretas del asentamiento en una disposición alveolar (Ruano 2015: 45-50). En ocasiones podemos interpretar la coexistencia de tres o más de estas estructuras en áreas de intensa utilización, en donde se advierten también superposiciones claras de estructuras circulares de esta clase en un lapso de tiempo reducido. Un ejemplo elocuente de este tipo de ocupación lo hallamos en la superposición de las estructuras C31, C22 y C20, que tendremos ocasión de comentar.

Esta imagen de un poblado formado por estructuras de planta circular es sustituida posteriormente por una ordenación más tardía del hábitat a partir de estructuras de plantas cuadrangulares. La secuencia formada por las cabañas C15 y R13 es especialmente ilustrativa de este proceso. También lo es la superposición de R3 respecto de R1, aunque R3 corresponda a una tipología aún posterior. Ciertamente, las transformaciones del poblado no terminan con la construcción de viviendas de planta cuadrada. Todavía advertimos una última evolución arquitectónica del conjunto, cuando algunas de las cabañas cuadradas son ampliadas y pasan a adoptar plantas rectangulares de mayores dimensiones. La ampliación de la estructura cuadrangular R15, que originariamente responde a una construcción de tipo $\mathrm{C}$ y que se convierte en otra mayor de tipo D nos servirá para explicar este cambio. Esta nueva estructura - más grande - puede interpretarse como coetánea de R3, que se construye sobre la amortización de un espacio de producción que inutilizó a su vez la cabaña circular $\mathrm{C} 1$, anteriormente mencionada, que ocupo el espacio en primer término.

\section{CONSTRUCCIÓN, RECONSTRUCCIÓN Y TRANSFORMACIÓN DEL HÁBITAT EN REVENGA}

Dado que no disponemos todavía de una secuencia estratigráfica que permita reconstruir la primera fase de ocupación del antiguo poblado de Revenga, debemos centrarnos por ahora en los procesos de transformación posteriores, a la espera de que los trabajos arqueológicos futuros permitan completar el registro. La excavación de una superficie rocosa amplia que se extiende al norte de la necrópolis (RM6) ha permitido documentar la existencia de una concentración notable de estructuras de planta circular en disposición alveolar. Nos referimos al conjunto formado por los fondos de cabaña que identificamos como C20, C21, C22, C23 y C31 (Fig. 6).

Entre ellos, los dos últimos corresponden a las estructuras más antiguas, de las que apenas conservamos estratigrafia. Distintos encajes y hasta cuatro postes cercanos a C23 son el único testimonio de una edilicia en materiales perecederos. Resulta imposible por ahora estimar la duración de este tipo de viviendas, que debieron ser sometidas a apuntalamientos y remociones frecuentes, pues en este mismo espacio reducido, de apenas $30 \mathrm{~m}^{2} \mathrm{de}$ superficie, se documentan hasta tres superposiciones de estructuras de características muy similares.

En ellas se advierten una serie de elementos comunes: la base de la cabaña es sometida a un trabajo de regularización del suelo rocoso, en ocasiones nivelando las posibles oquedades o irregularidades mediante una preparación de pavimento con canto rodado o un mortero algo rústico formado por arenisca machacada. Sobre esta superficie más o menos regular, una capa fina de arcilla batida constituye el suelo de uso de la cabaña, sin mayores acabados. Estos suelos arcillosos soportan la actividad cotidiana y a menudo conservan sobre su superficie algunos fragmentos de cerámica, pequeños carbones y 

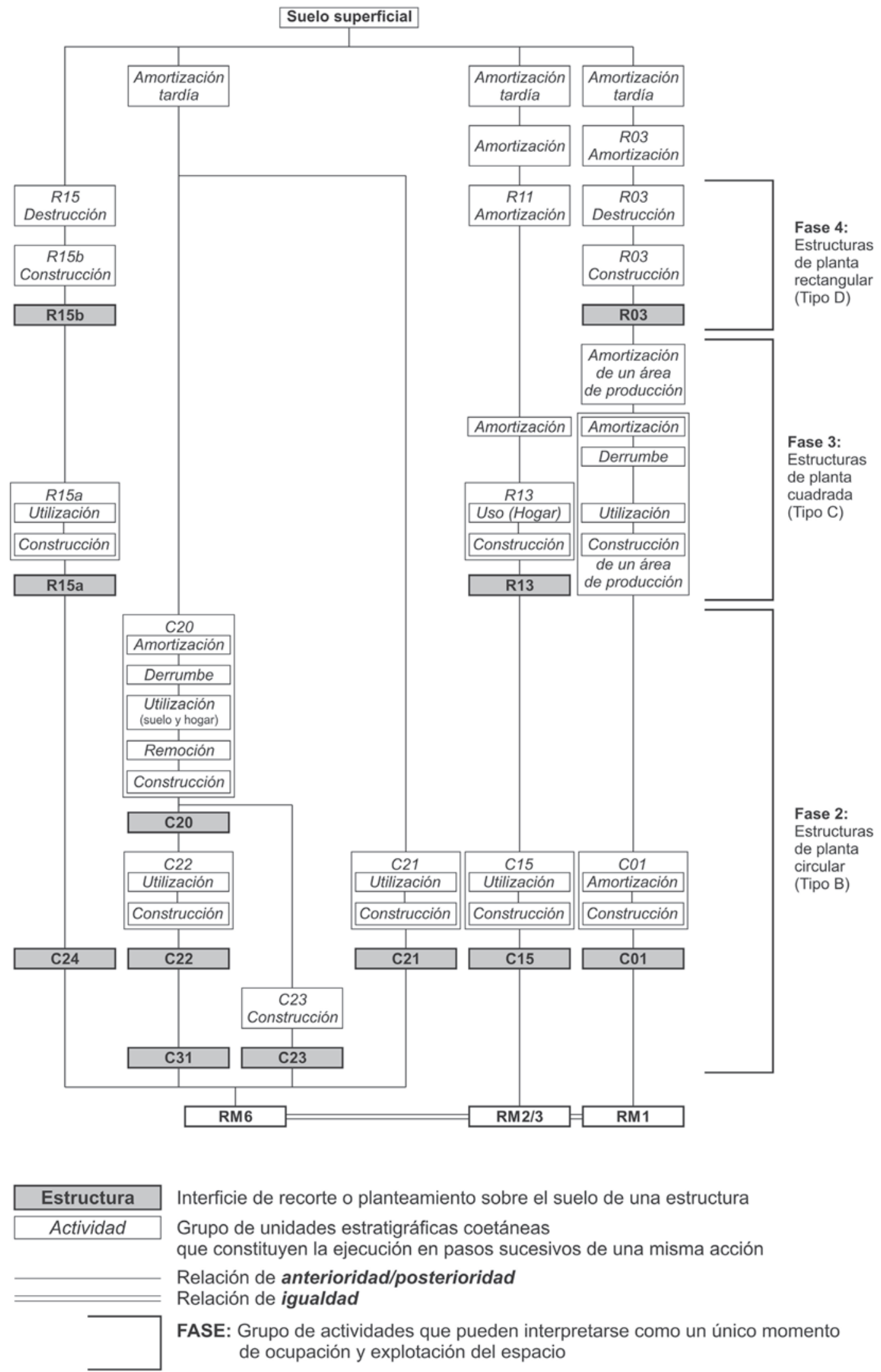

Interficie de recorte o planteamiento sobre el suelo de una estructura Grupo de unidades estratigráficas coetáneas que constituyen la ejecución en pasos sucesivos de una misma acción Relación de anterioridad/posterioridad Relación de igualdad

FASE: Grupo de actividades que pueden interpretarse como un único momento de ocupación y explotación del espacio

Figura 5. Matriz de actividades simplificada, limitada a las estructuras seleccionadas para el presente trabajo y a las relaciones que se establecen entre ellas. 

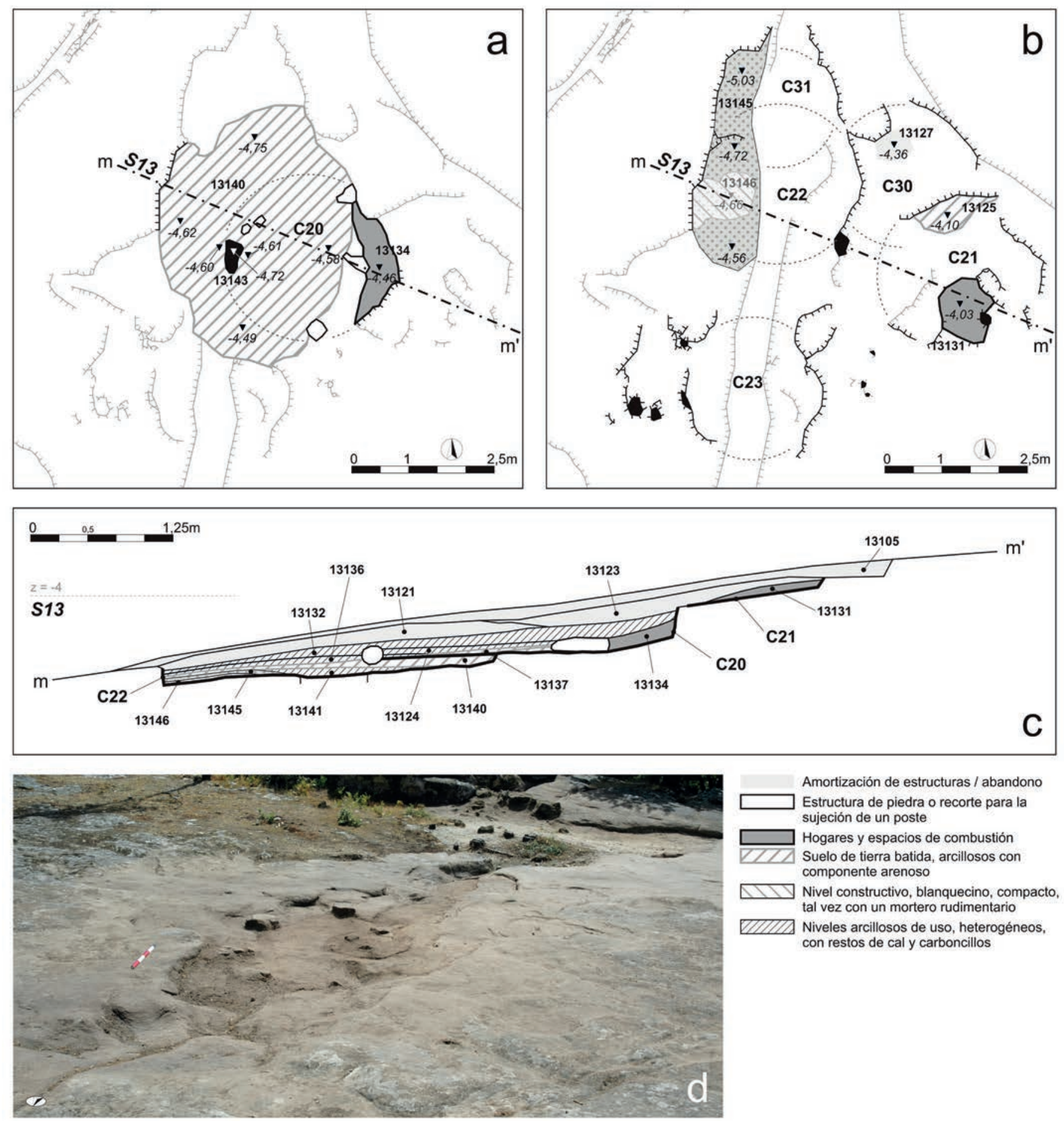

Figura 6. Documentación gráfica relativa a la reutilización de estructuras de tipo b: Fase de construcción de la estructura C20 (a), restos constructivos del conjunto de estructuras C21, C22 y C23 (b), sección ilustrativa del proceso de ocupación del espacio (c) y vista general del sector (d).

habitualmente los restos de algún hogar. La ubicación de estos hogares dentro del habitáculo casi siempre aprovecha alguna pequeña cubeta - tal vez de origen natural o someramente acondicionada a tal efecto- que permita un mayor control del fuego. Tal es el caso del pequeño hogar detectado en el lateral de la estructura C21.
Los niveles constructivos y de utilización de esta estructura, así como de la contigua $\mathrm{C} 22$, aparecen fuertemente afectados por la construcción de un habitáculo posterior de rasgos muy parecidos. La nueva cabaña circular C20 arrasa a C21 mediante la talla de un semicírculo bien marcado sobre el suelo rocoso, de unos 
$20 \mathrm{~cm}$ de profundidad en su lado oriental. En la parte occidental la planta aparece mucho menos marcada sobre el suelo de arenisca, porque amortiza en parte los antiguos niveles constructivos de la cabaña predecesora depositando sobre ellos una capa arcillosa con abundante componente arenoso que regulariza y consigue homogeneizar un profundo desnivel que existía entre las dos construcciones más antiguas. Nada parece indicar que haya un especial interés en cubrir o eliminar por completo los restos de la antigua cabaña $\mathrm{C} 21$, al quedar estos fuera del nuevo edificio.

La planta de la nueva estructura aparece delimitada por una serie de piedras sin talla, irregulares y de grandes dimensiones, que junto con un agujero de poste, tallado en los niveles de amortización y relleno de gravillas, completa por occidente la forma circular que se advierte en el área oriental. Nuevamente adosadas al recorte rocoso, aparecen trazas de rubefacción y una capa negra con manchas cenicientas que interpretamos como hogar y que aparece en relación con dos suelos consecutivos como mínimo. La elevada concentración de estructuras en un espacio de pequeñas dimensiones sugiere la reconstrucción frecuente de unas cabañas algo precarias que parecen desplazarse entre uno y dos metros con cada nuevo levantamiento.

Esta remoción y reconstrucción de estructuras muy similares difiere de la secuencia excavada unos cincuenta metros al este sobre el afloramiento rocoso identificado como RM2. En este caso, una estructura de planta cuadrangular (R13) de tipo $\mathrm{C}$ y de unos $15 \mathrm{~m}^{2}$ de superficie se superpone a una estructura circular previa (C15) que aparece inutilizada en su totalidad (Fig. 7). La ocupación previa del espacio que ocupará R13 y su posterior amortización ofrecen una superficie más o menos extensa y regular, que no requiere de excesivos trabajos de labra rupestre. De este modo, la esquina sur de la construcción aparece bien tallada sobre la roca dado que se trata de la cota superior del suelo de arenisca, por lo que necesita un rebaje mayor a fin de nivelarlo con el extremo norte, en donde el rebaje del cimiento se hace mucho más difuso.

Esta construcción probablemente contara con un zócalo de piedra de unos $70 \mathrm{~cm}$ de ancho y una edilicia superior que desconocemos, probablemente en tapial o madera. Un elemento especialmente llamativo de esta cabaña es el hogar situado en la esquina oriental del edificio (Fig. 7 a y d). Este hogar aprovecha una diaclasa natural de la roca, ensanchada en la zona de contacto con la estructura, que parece funcionar como tiro de ventilación de la habitación. Esta cabaña, a una cota muy poco profunda y prácticamente destruida a ras de suelo, no ha permitido recuperar más indicios de su superficie de uso.

La amortización de estructuras antiguas en un momento de reestructuración del poblado y la construcción de edificios de planta cuadrada ha permitido preservar el suelo y los niveles constructivos de las estructuras precedentes, de planta circular. Tal es el caso de la cabaña $\mathrm{C} 15$, del tipo B. Bajo la capa de nivelación que amortiza los restos de la estructura y sobre la que se construye la cabaña cuadrada, se ha recuperado prácticamente íntegro un suelo de uso, de planta circular, bien compactado, de arcilla con un componente arenoso que confiere a la superficie un carácter algo rugoso y sobre el cual se documenta un hogar en la zona central, ligeramente desplazado hacia un lateral. Bajo la estratigrafía relacionada con la utilización de la cabaña, se han conservado también los niveles constructivos de la misma.

El suelo aparece nuevamente regularizado y uniformizado mediante la deposición de una capa blanquecina, dura y bien prensada, común a muchas otras estructuras del yacimiento, que interpretamos como un mortero de cal sencillo, de características y consistencia variable en las distintas estructuras del yacimiento. Este mortero se limita a rellenar las oquedades del suelo, como en ocasiones precedentes. En el espacio sudeste de la cabaña, entre la capa de mortero y el suelo de uso arenoso se detectan los restos de una capa arcillosa de finalidad incierta. Podría relacionarse con el espacio ocupado por los hogares tal vez como algún tipo de aislante, pero no disponemos de más evidencias al respecto. Dos encajes circulares, probablemente apoyos de poste, se relacionan con la estructura. La base de uno de ellos aparece también picoteada para el asiento de una pequeña capa de cantos, también siguiendo las técnicas de construcción habituales en el yacimiento.

Esta preparación de pavimento con cantos se advierte de manera prácticamente idéntica en una estructura contigua (C17) también circular de tipo B. En ella, los niveles de uso prácticamente no se han preservado y el conjunto aparece algo más arrasado, probablemente por quedar fuera del edificio posterior (R13). En este caso, la preparación de pavimento con canto rodado aparece dispuesta a modo de corona circular alrededor de los límites de la estructura, mientras que la parte central queda uniformizada por la capa de argamasa. En la zona central, ligeramente desplazada, se descubre una acumulación de piedras irregulares, de pequeña entidad, interpretable quizás como base de algún tipo de soporte vertical de la cubierta. 

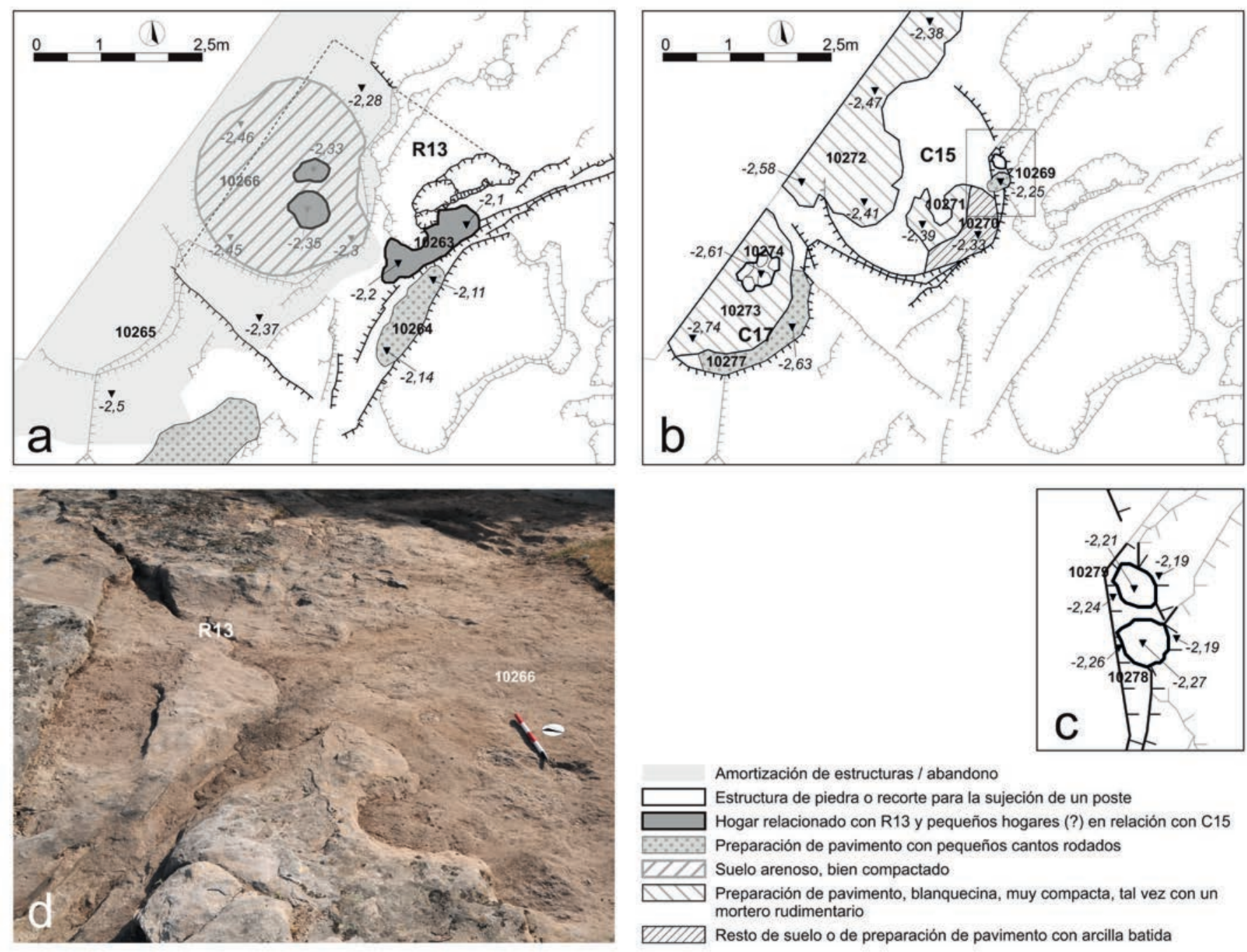

Figura 7. Documentación gráfica relativa a la secuencia de las estructuras R13 y C15: fase de ocupación de R13 (a) y fase de construcción de C15 (b). Detalle de los postes identificados en relación con C15 (c) y vista general del conjunto (d).

En los casos en que hemos recuperado superposiciones de estructuras cuadradas o rectangulares sobre otras de planta circular, la estratigrafía de ambas fases acostumbra a estar separada por un nivel de amortización más o menos potente que homogeneiza el suelo y cubre los restos de la actividad precedente. En cambio, esto no sucede en el proceso que interpretamos como reconstrucción de estructuras de la segunda fase, ni en la ampliación de estructuras como la que documentamos en el caso de R15, sobre el suelo rocoso de la floración identificada como RM6, muy cercanas al conjunto de estructuras circulares anteriormente descrito.

Esta cabaña cuadrada de tipo $C$, de unos $11 \mathrm{~m}^{2}$ de superficie, es ampliada hasta doblar el área ocupada y se transforma en una nueva estructura de $22 \mathrm{~m}^{2}$ y planta rectangular de tipo D. La interpretación de estos restos es significativa porque presenta paralelos muy evidentes con el proceso de ampliación y reconstrucción del edificio de culto presentado en trabajos anteriores (Padilla y Álvaro 2011a: 71-75, 2011b: 442-444, 2013: 18-26). Tal como sucede con la iglesia de Revenga, los vestigios rupestres que atestiguan la presencia de la estructura R15 en sus distintas fases aparecen marcados sobre un mismo horizonte pétreo, un plano atemporal que debe ser analizado en detalle para vislumbrar la evolución del edificio en sus distintas fases constructivas.

El primer edificio de planta cuadrangular inutiliza las fases previas de poblamiento del sector, densamente ocupado por cabañuelas circulares en disposición alveolar (Fig. 8). Sobre la superficie de la roca se advierte un rebaje cuadrangular, muy poco profundo, delimitado al noroeste por tres postes de idénticas características $-15 \mathrm{~cm}$ de diámetro y entre 3 y $4 \mathrm{~cm}$ de profundidad- y perfectamente alineados. Al sudeste, un recorte 
longitudinal de la roca parece constituir el asiento de un murete o zócalo y dos encajes irregulares parcialmente recortados y opuestos entre sí completan el cuadrado a lado y lado de la estructura, cuya entrada se habría situado en la pared sudeste (Fig. 8 a).

Poco más podemos saber de las características de esta edificación antigua. Sobre el suelo se documentan de manera muy precaria y fragmentada pequeñas acumulaciones de canto rodado, que rellena oquedades tenues y que aparece mezclado con gravillas y algo de arena. Estos parecen ser los únicos restos conservados de una preparación de pavimento cubierta por los suelos posteriormente eliminados tras la ampliación del edificio. Esta planta inicial fue alargada por los lados nordeste y sudoeste para construir un nuevo edificio de planta rectangular, casi el doble de largo y de igual anchura que el primero. La alineación de tres postes que documentábamos para la pared noroeste es alargada mediante nuevos postes, por lo que se podría deducir que esta pared se habría mantenido en pie al menos parcialmente y que el acceso al edificio habría seguido ubicado en la pared opuesta (Fig. 8 b).
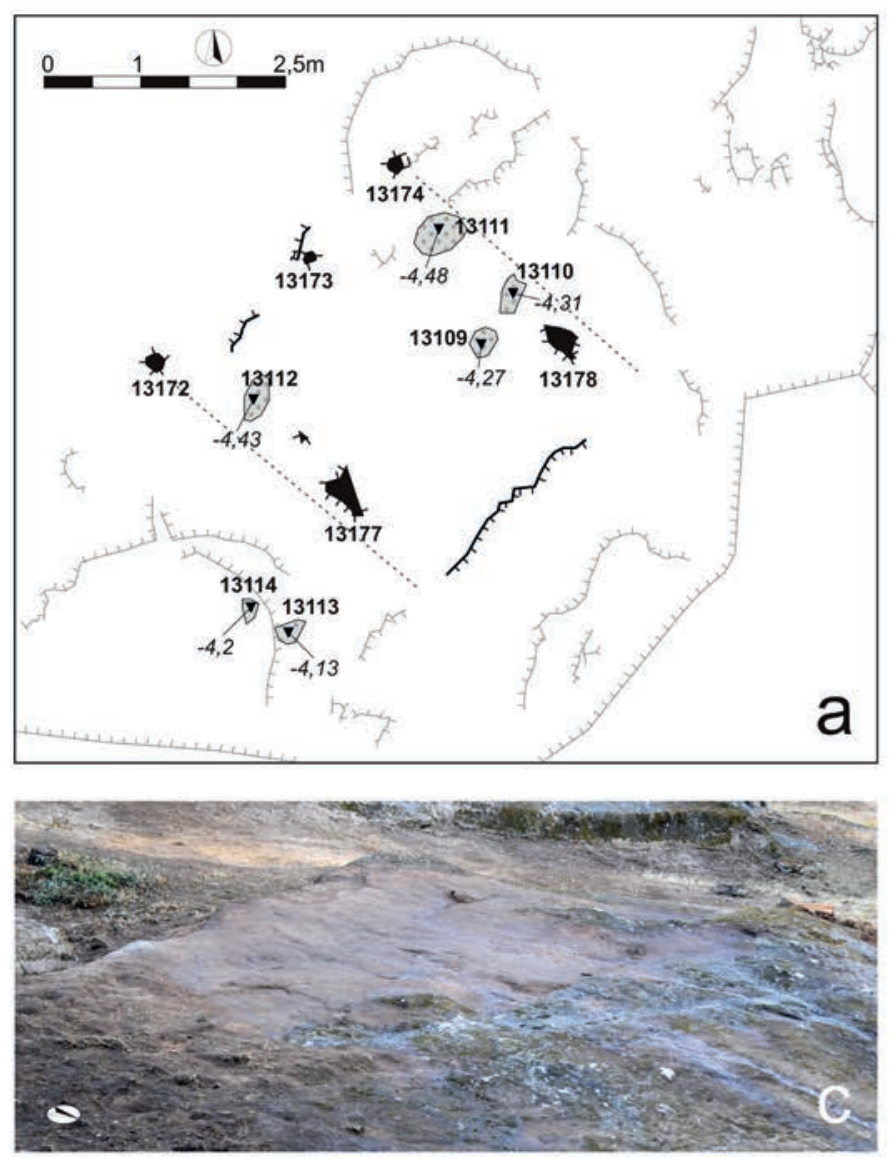

Toda la superficie es uniformizada por una preparación de pavimento más compacta, con esta preparación blanquecina a modo de mortero, que no se conserva tampoco en su totalidad. El espacio aparecía cubierto en el momento de su intervención por una capa de derrumbe, formada por piedras de dimensiones variables, sin talla, y algunos fragmentos de teja, que atribuimos a la fase final del asentamiento, cercana al siglo XIII. Esta estructura última habría contado, a tenor de los restos, con un zócalo de piedra al menos sobre el que se habrían terminado de levantar las paredes. El volumen de derrumbe conservado a pesar del expolio del lugar, no parece suficiente como para imaginar una cabaña construida en piedra en su totalidad por lo que intuimos que la edilicia en materiales perecederos se mantiene hasta las últimas fases del asentamiento.

Las características de esta construcción tardía corresponden a grandes rasgos con las de R3, situada sobre la floración rocosa RM1, unos treinta metros al este del promontorio que alberga el espacio sacro. En este caso la secuencia estratigráfica completa refleja la evolución

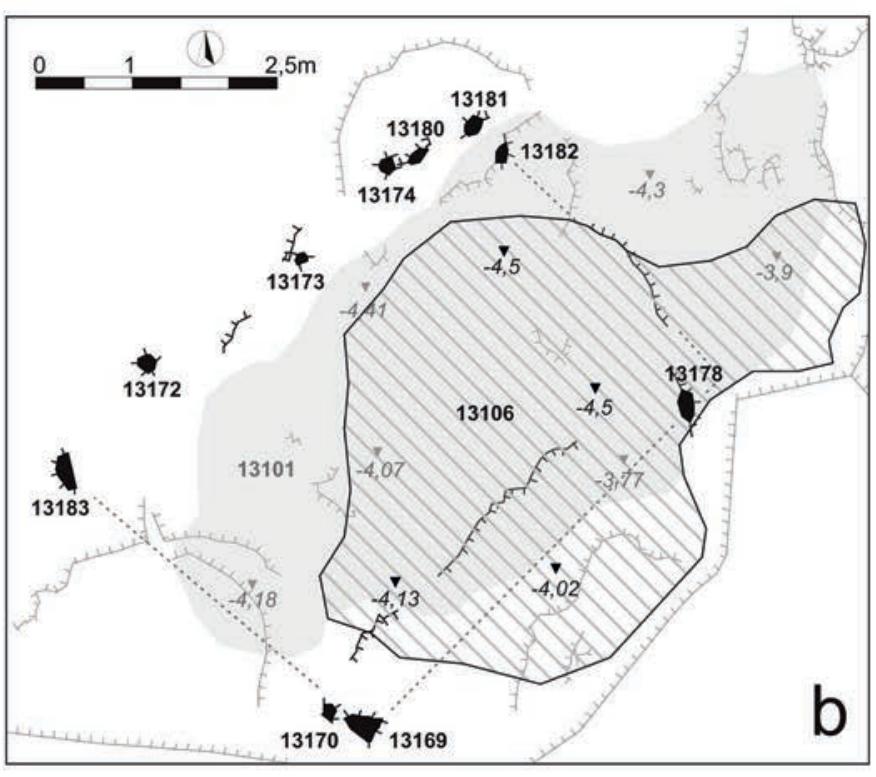

Amortización de estructuras / derrumbe

Recorte para la sujeción de un poste

Preparación de pavimento con pequeños cantos rodados

Preparación de pavimento, blanquecina, muy compacta, tal vez con un mortero rudimentario

ZIIIJ Resto de suelo o de preparación de pavimento con arcilla batida

Figura 8. Documentación gráfica de la ampliación de la estructura R15: fase de construcción de la estructura primitiva R15a y sus niveles asociados (a), ampliación de la construcción y niveles tardíos de derrumbe (b) y vista general del sector (c). 
entre las fases 2, 3 y 4 (Fig. 5), que se suceden de manera continuada. Sobre el lugar en donde se ubicó una antigua cabaña de planta circular $\mathrm{C} 1$, se construye en la fase final del asentamiento una estructura de planta rectangular (R3) y casi $25 \mathrm{~m}^{2}$ de superficie. Sin embargo, el espacio aparece continuamente ocupado porque entre la construcción más antigua y la más tardía se documenta un espacio de producción que parece coetáneo de la fase 3 del asentamiento (Fig. 9).
Esta intensa reutilización del sector impide conocer en profundidad los rasgos de la estructura $\mathrm{C} 1$, de la que sólo conservamos su impronta sobre el suelo de arenisca y una capa relativamente potente de sedimento relacionada con su amortización y nivelación posterior del sector para la planificación de este espacio de producción. El antiguo corte de la estructura circular es aprovechado para practicar un nuevo rebaje hacia el norte y construir una espacie de cubeta en forma de media luna. Al sur,
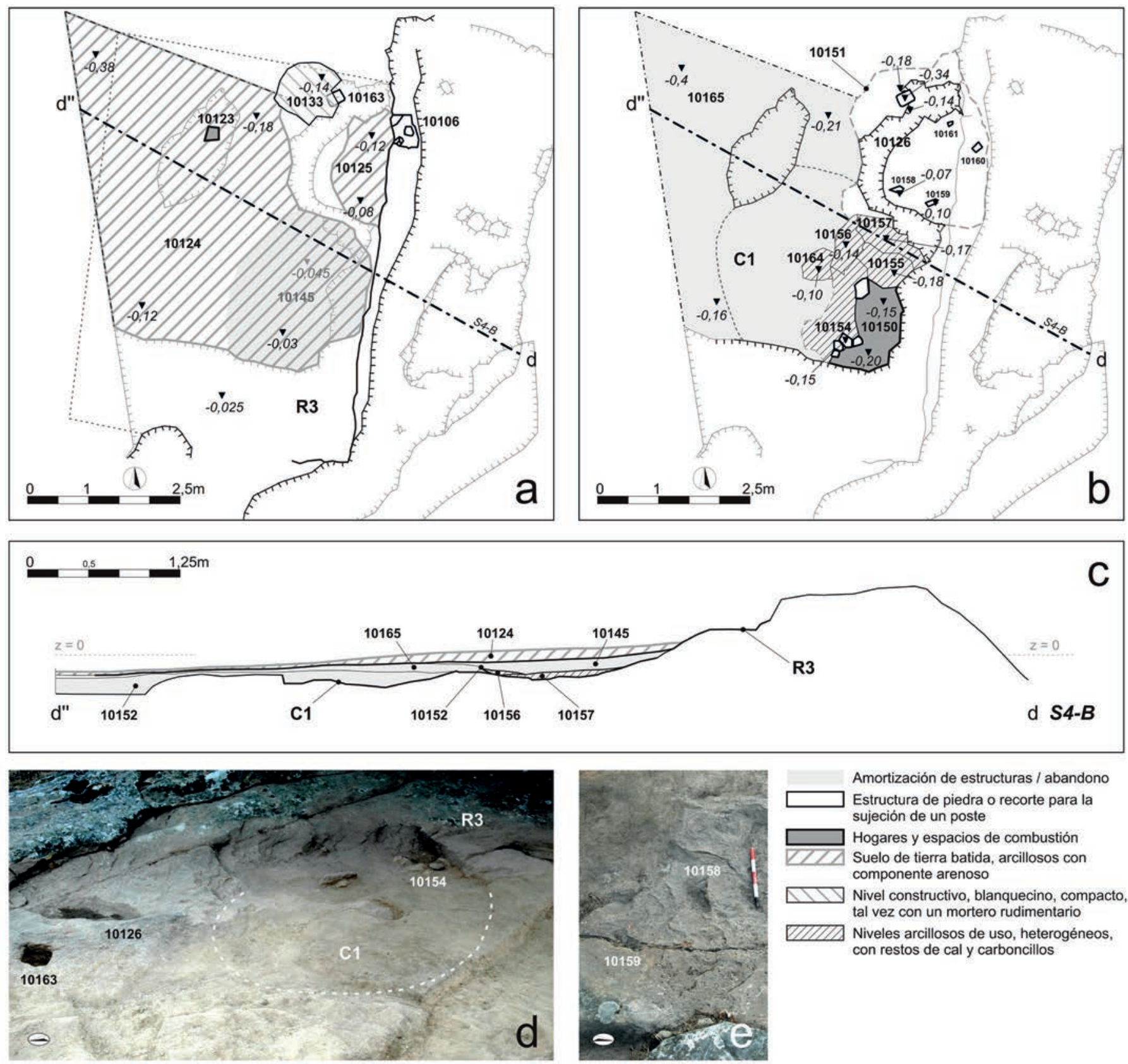

Amortización de estructuras / abandono Estructura de piedra o recorte para la sujeción de un poste

Hogares y espacios de combustión

Suelo de tierra batida, arcillosos con componente arenoso

Nivel constructivo, blanquecino, compacto, tal vez con un mortero rudimentario

Niveles arcillosos de uso, heterogéneos, con restos de cal y carboncillos

Figura 9. Documentación gráfica relativa a la secuencia de las estructuras R3 y C1: fase de ocupación de R13 (a), amortización de C1 para la utilización del espacio como área de producción (b), sección ilustrativa de la sucesión de estructuras (c), vista general del sector (d) y detalle de las marcas de desgaste sobre el suelo rocoso (e). 
la forma circular de la estructura se modifica para crear un ángulo recto que albergará un hogar de dimensiones considerables. De este modo, se construye una especie de corredor adosado, amparado en un considerable desnivel de la roca, que alberga algún tipo de actividad productiva quizás relacionada con el trabajo del metal.

Esta zona aparece amortizada con un nivel de derrumbe potente, con abundantes fragmentos de arenisca ocasionalmente muy rubefactados o con manchas cenicientas y de naturaleza heterogénea, a menudo con marcas de talla y encajes muy evidentes, y algunos fragmentos de cerámica reductora y teja de cronologías correspondientes a las fases más avanzadas del asentamiento. Estas características nos permiten sospechar de la existencia de algún tipo de estructura de combustión. Los niveles contiguos a esta presunta estructura parecen corroborar nuestra interpretación: pequeñas acumulaciones de materiales diversos en forma de lechadas arcillosas, arenosas, con mayor o menos cantidad de componentes calcáreos se amontonan entre los restos del hogar y la cubeta semicircular ubicada algo más al norte. Sobre esta cubeta, cuatro marcas de fricción (Fig. 9 e) en disposición rectangular corresponderían a la impronta dejada sobre el suelo de algún tipo de soporte apoyado de manera continuada sobre el suelo de arenisca.

Esta alternancia entre espacios de hábitat y de producción no es ajena a la dinámica habitual del asentamiento y se documenta también en otros puntos del mismo. Todo este espacio productivo será finalmente inutilizado y sustituido por un nuevo edificio de planta rectangular cuya superficie es cubierta por un pavimento de tierra batida, de color anaranjado que se ha preservado prácticamente en su totalidad, con una concentración de materiales cerámicos - muy fragmentados - algo superior a otros puntos del yacimiento. Esta cabaña más tardía probablemente contó con un zócalo de piedra, cuyos restos se advierten sobre el recorte de arenisca que constituyó la pared oriental y en el espacio de cierre de la pared norte.

Las cabañas de la última fase debieron de contar con una techumbre parcialmente cubierta de teja y quizás una pared de tapial. El acceso a esta vivienda estaría localizado en la pared meridional del edificio y contaría con un pequeño rellano ante la puerta de entrada delante de un desagüe que evacua la acumulación de agua hacia os niveles inferiores de un pequeño promontorio rocoso. Ciertamente, el suelo de arenisca desciende de forma algo brusca hacia el sur y el afloramiento de roca que identificamos como RM1 habría albergado distintas estructuras rectangulares, todas ellas con el acceso a mediodía y desagües asociados a cada una de ellas.
No podemos aventurar por ahora mucho más de las características del poblado y su evolución pero, a tenor de los restos recuperados y analizados hasta ahora, nuestra impresión es que las fases más antiguas del poblamiento se ubicaron en el espacio más cercano a la necrópolis, con anterioridad a su construcción, y que a medida en que la implantación del centro de culto y la delimitación del cementerio contribuyen a generar una nueva ordenación del espacio, la reestructuración del poblado transforma las estructuras de hábitat y las desplaza. Las nuevas viviendas abandonaran las formas circulares más antiguas y adoptaran la nueva apariencia cuadrangular que las caracteriza, a la par de se alejan progresivamente del área sacra. La impresión que tenemos por ahora del asentamiento sugiere que los fondos de cabaña de planta cuadrada y rectangular que hemos podido recuperar proporcionan únicamente una visión incompleta de un poblado que se extiende hacia el suroeste.

\section{CONSTRUCCIONES EN MATERIALES PERECEDEROS Y POBLAMIENTO ALTOMEDIEVAL}

Las características de las estructuras de hábitat que hemos analizado para el caso de Revenga y la complejidad interpretativa que de ellas se deriva no son en absoluto ajenas a la problemática general de este tipo de asentamientos en el espacio peninsular y europeo. Uno de los problemas centrales del estudio del hábitat rural entre los siglos V y IX gira en torno a la individualización de viviendas y edificaciones diversas construidas con materiales perecederos, fundamentalmente tierra y madera (Hamerow 2012; Peytremann 2012; Vigil-Escalera 2003), y a la relación que se establece entre esta transformación del sistema constructivo y las dinámicas socioeconómicas propias del momento.

El rasgo más significativo de este cambio en la construcción es que se generaliza a partir de los siglos IV-V para la mayoría de territorios y que debe relacionarse con un proceso de transformación de las formas de ocupar y gestionar el espacio y los sistemas de producción. Aquellos argumentos que tradicionalmente habían proporcionado una identificación de carácter étnico a este tipo de edilicia, vinculándola con la entrada y asentamiento de los pueblos germánicos (Brogiolo 1996), han quedado ya ampliamente superados (Quirós 2011: 77; Quirós y Vigil-Escalera 2011: 273-174; Augenti 2004). Ello no es obstáculo, sin embargo, para 
reclamar unos análisis que deben llevarse a cabo para cada territorio en función de los contextos específicos y que necesariamente deben huir de unas generalizaciones que se revelan a la larga imposibles.

El panorama actual de las investigaciones nos muestra cómo la construcción en madera no es exclusiva de una realidad política, social o económica concreta ni de un mismo proceso evolutivo de estas realidades múltiples y heterogéneas. De este modo, en contextos arqueológicos vinculados con la presencia de villas romanas de época bajoimperial se registra una transformación de usos en relación con estas nuevas formas de construcción y con la presencia de sistemas de almacenamiento, fundamentalmente silos (Quirós 2011: 73; Vigil-Escalera 2007: 246), que han sido interpretados por múltiples autores como elementos que demuestran un control de la producción en manos de las comunidades campesinas que empiezan a desarrollarse con autonomía de los sistemas de poder establecidos (Tejerizo 2016: 390; Vigil-Escalera 2007: 244; Quirós 2014: 148).

En Revenga no hemos recuperado ningún elemento claramente identificable como silo, con los rasgos propios de estos espacios de almacenaje tal como se han recuperado en otros yacimientos (Quirós 2013; Roig 2013; Rodríguez 2013; Vigil-Escalera 2013). Si bien es cierto que las estructuras circulares de la primera fase responden a unas dimensiones en exceso reducidas como para conformar un espacio de habitación, también lo es el hecho de que no contamos con elementos suficientes para interpretar con seguridad su distribución y funcionamiento. Carecemos por ahora de elementos suficientes para una posible identificación como silos de dichas estructuras dado su nivel de arrasamiento y la ausencia de una estratigrafía clara que se les asocie. Además, las características de distribución alveolar que detectamos en la segunda fase de ocupación del asentamiento podrían haber estado vigentes durante el periodo más antiguo. En cualquier caso, no disponemos de argumentos sólidos que nos permitan hablar de un control de la producción campesina, en parte porque en el territorio que constituye nuestro objeto de análisis la agricultura parece a todas luces una actividad secundaria, cuando no inexistente, siendo la ganadería y las actividades silvopastoriles el medio primordial de subsistencia (López, Álvaro y Travé 2016b: 176), actividad que en ningún caso es ajena a otras realidades altomedievales en unas economías cada vez más localistas (Wickham 2013: 191).

Sin embargo, estas construcciones - a menudo interpretadas como el resultado una traslación de los agentes de control de la producción de los grupos aristocráticos a las comunidades campesinas - también constituyen elementos propios de los espacios identificados como contextos germánicos, especialmente en el norte de Europa y la Gran Bretaña (Hamerow 2012) de los siglos VI-VIII. En estos contextos, la edificación en materiales perecederos podría considerarse un cambio arquitectónico originado por las nuevas comunidades que se instalan en el territorio y que mantienen algunos de los rasgos característicos de sus lugares de origen, entre ellos la edilicia en madera. En cualquier caso, la imposibilidad de identificar con claridad la adscripción étnica de los pobladores en ausencia de ajuares y a partir de unos materiales cerámicos en buena medida desconocidos también debería interrogarnos acerca de la validez de estas asociaciones, lo que nos adentra en un debate espinoso (Vigil-Escalera 2000: 248).

También resulta significativo el hecho de que este tipo de construcciones se documentan con la misma frecuencia en aquellos espacios periféricos que parecen haberse mantenido al margen de los grandes poderes establecidos en época romana, en lo que algunos autores denominan "otras formas de asentamiento rural" (Schneider 2007: 21-23) o, como hemos comentado en las páginas iniciales de nuestro trabajo, la delimitación de espacios de periferia. Tanto es así que la interpretación de asentamientos relativamente cercanos (Gómez 2008) situados en las vertientes exteriores del espacio que identificamos como la Alta Sierra, en la cabecera del Arlanza, difiere en cierto modo de los rasgos que concluimos para Revenga, puesto que la relación del asentamiento con el territorio circundante y su situación sociopolítica previa también es diferente.

Ante la variabilidad y pluralidad de las distintas realidades de poblamiento en relación con múltiples realidades territoriales, nuestra propuesta interpretativa pasa por delimitar con claridad las características del entorno inmediato de estos asentamientos (Alvaro 2012: 49-98; López, Álvaro y Travé 2016a: 21-35, 2016b: 175-179), es decir, llevar a cabo un análisis exhaustivo del paisaje, de las relaciones entre asentamientos y de los rasgos internos de cada uno de ellos, a fin de definir el alcance de la influencia de los poderes establecidos. En dicho análisis deberíamos ser capaces también de reconocer las limitaciones de dichos poderes en el control exhaustivo del territorio. Se trata, pues, de interpretar la relación de las comunidades humanas con el territorio en función de una gran multiplicidad de variables que lo afectan y lo construyen de forma consciente y específica (Hicks 2016). En este sentido, la excavación del asentamiento de Revenga nos podrá ser de utilidad como referencia para abordar el 
poblamiento en Cuyacabras, La Cerca o en los enclaves más inmediatos que comparten un mismo entorno serrano. Sin embargo, a medida en que descendamos de cota y nos adentremos en un territorio mejor comunicado y más romanizado, un registro arqueológico similar deberá ser interpretado en base a otros parámetros necesariamente distintos (Gómez 2008).

A nuestro parecer, también es necesario mostrar cierta prudencia con la lectura de estos asentamientos en clave de estratificación social. En el marco de un registro arqueológico en el que, por lo general, conocemos de manera precaria las características de estas estructuras, utilizar variables relativas como las dimensiones, por ejemplo, para interpretarlas como un indicador de preeminencia social es simplista y a todas luces problemático, tal como ya han hecho notar algunos autores (Ulmschneider 2010: 161). En el caso de Revenga, el análisis en profundidad de las estructuras de habitación no revela la presencia de ningún grupo social privilegiado, lo que tampoco excluye la posibilidad de que lo hubiera. Simplemente, desconocemos la naturaleza social en términos de estratificación y jerarquía de los habitantes de este entorno de montaña.

$\mathrm{Si}$ algún rasgo del asentamiento de Revenga puede ser interpretado en términos sociales es la progresiva formación de una distribución de poblamiento que tiende a la concentración, pero que en ningún momento se prefigura como compacto y que mantiene un cierto carácter disperso en el seno del asentamiento. La pérdida del carácter alveolar de las cabañas más antiguas, de muy pequeñas dimensiones, pero con varios edificios juntos, probablemente utilizados de manera comunal o colectiva, y su evolución hacia una forma de poblamiento en la que cada una de las cabañas rectangulares parece constituir un espacio residencial más o menos individualizado dentro del asentamiento, podría llevarnos a pensar en un proceso de transformación de la célula básica que ocupa un mismo espacio de hábitat. Esto es la consolidación de la familia nuclear que, habitando un espacio propio circunscrito a las necesidades de un grupo familiar reducido, comparte con otras familias un mismo espacio y entre todos lo explotan en vecindad de manera colectiva (Mínguez 2004: 175).

Esta relación de la familia con la colectividad, se manifiesta también en la práctica religiosa, ordenada a partir del centro de culto y el cementerio, en un proceso de construcción del paisaje cristiano (García de Cortázar 2012: 91; Wickham 2013: 96-97; Lauwers 2010), mientras que la intimidad del hogar genera un espacio de privacidad inexistente en las formas de organización social de tipo gentilicio más antiguo que conocemos para estos espacios de montaña. En este sentido, si intentamos buscar una explicación social a la transformación del espacio de hábitat, deberíamos vincularla al propio proceso de cristianización y a una lenta transformación de la sociedad hacia unos grupos familiares no tan extensos (Mínguez 2004: 174), a la par que evoluciona la construcción del cementerio cristiano.

Un último elemento que conviene poner sobre la mesa es la idea de rusticidad o empobrecimiento que a menudo impregna los planteamientos interpretativos de este tipo de viviendas y que, en todo caso, es un juicio de valor innecesario (Azkárate y Quirós 2001: 28). Las transformaciones en las formas de construcción necesariamente deben vincularse a un cambio de usos (Tejerizo 2016: 387) y a una transformación de las necesidades. En el poblado de Revenga observamos con frecuencia como se economizan esfuerzos y recursos a la hora de acondicionar unos espacios para los cuales se cuenta con los restos de una ocupación previa. Los trabajos de labra del suelo rocoso quedan a menudo limitados a la mínima expresión en aquellos casos en que se cuenta con precedentes de habitáculos anteriores o en el que las propias diaclasas naturales de la arenisca pueden ser utilizadas con fines constructivos.

Es necesario poner en duda que esta capacidad de adaptación pueda ser valorada en términos de rusticidad. Cabe preguntarse si las comunidades que pueblan este espacio construyen sus viviendas de la forma expuesta a lo largo de este trabajo porque no saben construirlas de otra manera y porque no dominan técnicas constructivas más sofisticadas, o bien - lo que parece mucho más verosímil- porque tal vez no las necesiten. En cualquier caso, conviene remarcar que la presencia de cubiertas de teja, especialmente en el período más tardío, así como los procesos de reconstrucción y remoción del asentamiento en su totalidad en determinados momentos probablemente requirieron - pese a trabajar con material perecedero- de una cierta especialización y de unos fundamentos mínimos de albañilería que algunos de los habitantes poseyeran o tal vez solicitaran a personal externo (Quirós 2011: 78).

\section{CONCLUSIONES}

El yacimiento de Revenga es un centro paradigmático para el conocimiento del poblamiento altomedieval y de las formas de asentamiento de las comunidades rurales en un espacio de montaña. Una particularidad remarcable del enclave, junto con otros yacimientos del lugar, es el carácter de aislamiento que le confiere la altitud, y que 
relega este territorio a un plano secundario dentro de los procesos de integración y control del espacio articulados desde los centros de poder bajoimperiales o visigodos.

El poblamiento en Revenga responde a un proceso de reestructuración constante. El asentamiento se transforma a medida en que surgen nuevas necesidades, tal vez vinculadas con un aumento de población que quizás incorpore en determinados momentos la llegada de agentes externos. Por ahora, la transformación más significativa del poblado parece vinculada con el proceso de cristianización de la zona, sin que ésta pierda todavía su carácter de periferia. Esta es nuestra hipótesis de trabajo en la actualidad para explicar unas transformaciones muy complejas de interpretar en términos de organización social, puesto que - en realidad - los rasgos del hábitat que advertimos en este yacimiento no difieren excesivamente de las características generales de los asentamientos construidos en material perecedero, propios de los momentos de transición entre el mundo bajo imperial y la alta edad media, que se advierten de forma similar en todo el occidente europeo.

Para el caso concreto de Revenga, sin embargo, el estado actual de las investigaciones nos permite poner sobre la mesa una serie de constataciones novedosas que deben marcar las líneas maestras de las intervenciones a realizar en los años siguientes: En primer lugar debemos destacar la continuidad de un asentamiento cuyo abandono datamos hacia el siglo XIII, momento para el cual ya contamos con fuentes escritas algo más abundantes. La estructura del poblamiento y los espacios de hábitat y producción se transforman en varias ocasiones, sin que se adviertan periodos de abandono entre unas y otras. El cambio más significativo en esta estructura es el paso de unos espacios de planta circular anterior a la implantación del centro de culto y la necrópolis a otra estructura de ocupación formada por cabañas de planta cuadrada que se organizan alrededor del espacio sacro.

La construcción del centro de culto presidiendo el asentamiento y la necrópolis de sepulturas rupestres a su alrededor está claramente vinculada con el proceso de cristianización de este espacio de montaña, aún con algunos visos de paganismo o de prácticas poco ortodoxas (Wickham 2013: 229), a juzgar por las enigmáticas insculturas presentes en el atrio de la iglesia primitiva (Padilla y Álvaro 2011b). En base a este momento de transformación vinculado a un momento de cristianización alrededor de los siglos VII-VIII, tenemos que considerar la existencia de un poblamiento anterior, relacionado con las cabañas de planta circular, articuladas en dos fases sucesivas; y aún de una reestructuración posterior, bastante más tardía, quizás en relación con la incorporación del enclave en las estructuras de control del territorio vinculadas con el condado de Castilla.

Así pues, las estructuras de planta circular diseminadas de manera uniforme por el yacimiento no respetan el espacio sacro que delimita posteriormente el cristianismo y ponen de manifiesto la existencia de un poblamiento anterior a la cristianización del espacio. Estas fases antiguas, que datamos alrededor de los siglos IV-VI destacan por la ausencia de elementos propios del mundo romano, en especial de materiales cerámicos tardíos o residuales, pero que difieren de los elementos propios de la cultura material posterior, que nos resultan algo mejor conocidos, a pesar de los numerosos vacíos que todavía existen en este campo. En este sentido, debemos llamar la atención sobre el desconocimiento que aún existe sobre este tipo de materiales y de las dificultades existentes a la hora de buscar paralelos al respecto. Por ello, la estrategia por ahora debe centrarse en la caracterización precisa de estas producciones que permita construir elementos de referencia fiables. Por ahora, apuntamos hipótesis de trabajo y reflexiones respecto de la organización del enclave en las que deberemos profundizar a medida que avance la investigación.

\section{AGRADECIMIENTOS}

Este trabajo se en incluye entre las tareas habituales del Grupo de Investigación en Arqueología Medieval y Postmedieval de la Universitat de Barcelona (GRAMP. UB), reconocido y consolidado por la Generalitat de Catalunya (2017 SGR 833 GRC). La investigación presentada forma parte de los resultados del proyecto I+D titulado "La formación del paisaje medieval: el origen de la red aldeana en el Alto Arlanza" (HAR2012-33673 MINECO/FEDER.UE), bajo la dirección de M. D. López. Debemos hacer contar también nuestro agradecimiento a las instituciones que han colaborado en la consecución del mismo: Diputación de Burgos, Junta de Castilla y León y Comunero de Revenga (Ayuntamientos de Quintanar, Canicosa y Regumiel de la Sierra).

\section{BIBLIOGRAFÍA}

Álvaro, K. 2012: El poblamiento altomedieval y sus manifestaciones funerarias en la cuenca del Alto Arlanza (s. $I X-X$ ). Tesis doctoral. Universidad de Barcelona [en línea] http://hdl.handle.net/10803/80651 [consultado el 05/06/2017]. 
Álvaro, K. y Padilla, J. I. 2012: “Arquitectura religiosa y necrópolis rupestres entre el Alto Arlanza y la cabecera del Duero (ss. IX-XI)", Hortus artium medievalium, 2012, pp. 445-458.

Addyman, P. V. y Leigh, D. 1973: "The Anglo-Saxon Village at Chalton, Hampshire: Second Interim Report", Medieval Archaeology, 17, pp. 1-25.

Augenti, A. 2004: "Luoghi e non luoghi: palazzi e cità nell'Italia tardoantica e altomedievale", en P. Boucheron y J. Chiffoleau (eds.), Les palais dans la ville. Espaces urbains et lieux de la puissance publique dans la Méditerranée Médievale, pp. 15-38. Lyon.

Azkárate, A. y Quirós, J. A. 2001: “Arquitectura doméstica altomedieval en la Península Ibérica: Reflexiones a partir de las excavaciones arqueológicas de la Catedral de Santa María de Vitoria-Gasteiz, País Vasco", Archeologia Medievale, 28, pp. 25-60.

Brogiolo, G. P. (ed.) 1996: La fine delle ville romane: transformazioni delle champagne fra tarda antichità e alto medioevo, $1^{\circ}$ Convegno archeologia del Garda (Gardone Riviera (Brescia 4 octubre 1995), Documenti di Archeologia, 11. Mantua.

Chapelot, J. 1980: "Le fond de cabanne dans l'habitat rural Ouest-Européen: État des questions", Archéologie Médiévale, 10, pp. 5-57.

Escalona, J. 2002: Sociedad y Territorio en la Alta Edad Media Castellana. La Formación del Alfoz de Lara. BARS1079, Oxford.

García de Cortázar, J. Á. 2012: Historia religiosa del Occidente medieval. Akal, Madrid.

Gardiner, M. 2012: "An Early Medieval Tradition of Building in Britain", Arqueología de la Arquitectura, 9, pp. 231-246.

Gómez, I. 2008: "El despoblado medieval de Loranco (Belorado, Burgos): En ejemplo arqueológico en torno a la configuración de la red aldeana de cronología Altomedieval", en J. F. Jiménez, J. Maiz, C. Villanueva y I. Calderón (eds.), Actas del IV Simposio Internacional de Jóvenes Medievalistas, pp. 77-91. Murcia.

Gutiérrez, J. A. 1998: "Sobre los orígenes de la sociedad asturleonesa: aportaciones desde la arqueología del territorio", Studia Historica. Historia Medieval, 16, pp. 173-197.

Hamerow, H. 2012: Rural Settlements And Society In Anglo-Saxon England. Oxford University Press, Oxford.

Hicks, D. 2016: "Temporality of landscape revisited", Norwegian archaeological review, 49, pp. 5-22. https://doi.org/10.1080/00293652.2016.1151458

Kirchner, H. 2010: "Sobre la arqueología de las aldeas altomedievales", Studia Historica. Historia Medieval, 28, pp. 243-253.

Lauwers, M. 2010: "Circuit, cimitière, paroisse, Réflexions sur l'ancrage ecclésial des sites d'habitat (VIIè-XIIIè siècle)", en J. M. Yante y A. M. Bultot-Verleysen, Autour du «village». Établissements humains, finages et communautés rurales entre Seine et Rhin (IVe-XIIIe siècles). Actes du colloque international de Louvain-la-Neuve, 16-17 mai 2003, Louvain-la-Neuve.

López, M. D., Álvaro, K. y Travé, E. 2016a: Yacimiento Arqueológico de Revenga. Iglesia, necrópolis, aldea. Diputación de Burgos, Burgos.

López, M. D., Álvaro, K. y Travé, E. 2016b: "Rock-cut Cemeteries And Settlement Processes At The Upper Arlanza Basin (Burgos, Spain): A Late Antique And Early Medieval Landscape Analysis", Zephyrus, 78, pp. 173-191.

Mínguez, J. M. 2004: "En torno a la génesis de las sociedades peninsulares altomedievales. Reflexiones y nuevas propuestas", Studia Historica. Historia Medieval, 22, pp. 169-188.

Padilla, J. I. y Álvaro, K. 2010: "Necrópolis rupestres y el poblamiento altomedieval en al Alto Arlanza (Burgos)", En la España Medieval, 33, pp. 259-294.

Padilla, J. I. y Álvaro, K. 2011a: "La pileta del despoblado medieval de Revenga (Burgos): a propósito del lavado ritual de los difuntos y sus evidencias arqueológicas", Pyrenae, 42/1, pp. 67-100.

Padilla, J. I. y Álvaro, K. 2011b: “Los grabados rupestres del despoblado medieval de Revenga (Burgos)", Munibe (Antropologia-Arkeologia), 62, pp. 439-459.

Padilla, J. I. y Álvaro, K. 2013: "Los asentamientos altomedievales del Alto Arlanza (Burgos). El despoblado medieval de Revenga", Pyrenae, 44/1, pp. $11-41$.

Peytremann, E. 2012: “The archaeology of early medieval (6th-12th) rural settlements in France", Arqueología de la Arquitectura, 9, pp. 213-230.
Quirós, J. A. 2011: "La arquitectura doméstica de los espacios rurales en torno al año 711", 711. Arqueología e Historia entre dos mundos. Zona Arqueológica, 15, pp. 63-82.

Quirós, J. A. 2013: "Silos y sistemas de almacenaje en el País Vasco en la Alta Edad Media", en A. Vigil-Escalera, G. Bianchi y J. A. Quirós (eds.), Horrea, barns and silos. Storage incomes in Early Medieval Europe, pp. 171-191. Universidad del País Vasco, Bilbao.

Quirós, J. A. 2014: "Aristocracias, poderes y desigualdad social en la primera Edad Media en el País Vasco", en R. Catalán, P. Fuentes y J. C. Sastre (eds.), Las fortificaciones en la tardoantigüedad: élites y articulación del territorio (ss. V-VIII d.C.), pp. 143-158. La Ergástula, Madrid.

Quirós, J. A. y Vigil-Escalera, A. 2011: "Dove sono i Visigoti? Cimiteri e Villagi nella Spagna Settentrionale dei secoli VI e VII", en C. Ebanista y M. Rotili (eds.), Archeologia e Storia delle migrazioni, Europa, Italia, Mediterraneo fra tarda età romana e Alto Medioevo, pp. 159-181. Cimitile.

Rahtz, P. A. 1976: "Buildings and rural settlements", en D. M. Wilson (ed.), The Archaeology of Anglo-Saxon England, pp. 49-98. Cambridge University Press, Cambridge.

Roig, J. 2013: "Silos, poblados e iglesias: almacenaje y rentas de época visigoda y altomedieval en Cataluña (siglos VI al XI)", en A. Vigil-Escalera, G. Bianchi y J. A. Quirós (eds.), Horrea, barns and silos. Storage incomes in Early Medieval Europe, pp. 145-170. Universidad del País Vasco, Bilbao.

Rodríguez, A. 2013: "Sistemas subterráneos de almacenamiento en la Galicia medieval. Una primera tipología y consideraciones para su estudio", en A. Vigil-Escalera, G. Bianchi y J. A. Quirós (eds.), Horrea, barns and silos. Storage incomes in Early Medieval Europe, pp. 193-208. Universidad del País Vasco, Bilbao.

Ruano, L. 2015: Arqueología de la Arquitectura aplicada a la Protohistoria del Occidente de Asturias (ss. I a.C.-d.C.): el hábitat doméstico en Coaña y San Chuis. Universidad Autónoma de Madrid. Trabajo de fin de máster inédito [en línea] https://www.researchgate.net/publication/309033731_ Arqueologia_de_la_Arquitectura_aplicada_a_la_Protohistoria_del_Occidente_de_Asturias_ss_I_a_C_-_d_C_el_habitat_domestico_en_Coana_y_ San Chuis [consultado el $06 / 06 / 2017$ ].

Schneider, L. 2007: "Structures du Peuplement et formes de l'habitat dans les campagnes du sud-est de la France de l'Antiquité au Moyen Age (IVèVIIIè s.): Essai de synthèse", Gallia: archéologie de la France antique latine, 64, pp. 11-56.

Tejerizo, C. 2014: "Estructuras de fondo rehundido altomedievales en la Península Ibérica", Munibe (Antropologia-Arkeologia), 65, pp. 215-237.

Tejerizo, C. 2016: "The end of the world as we know it: post-imperial social landscapes in North-Central Iberia (5th-6th Centuries)", Archeologia Medievale, 53, pp. 383-397.

Ulmschneider, K. 2010: "Settlement hierarchy", en H. Hamerow, D. A. Hinton y S. Crawford (eds.), The Oxford Handbook of Anglo-Saxon Archaeology, pp. 156-171. Oxford.

Vigil-Escalera, A. 2000: "Cabañas de época visigoda. Evidencias arqueológicas al sur de Madrid. Tipología, elementos de datación y discusión", Archivo Español de Arqueología, 73, pp. 223-252.

Vigil-Escalera, A. 2003: "Arquitectura de tierra, piedra y madera en Madrid (ss. V-IX d.C.).Variables materiales, consideraciones sociales", Arqueología de la arquitectura, 2, pp. 287-291.

Vigil-Escalera, A. 2007: "Granjas y aldeas altomedievales al norte de Toledo (400-850 d.C)", Archivo Español de Arqueología, 80, pp. 239-284.

Vigil-Escalera, A. 2013: "Ver el silo medio lleno o medio vacío: la estructura arqueológica en su contexto", en A. Vigil-Escalera, G. Bianchi y J. A. Quirós (eds.), Horrea, barns and silos. Storage incomes in Early Medieval Europe, pp. 127-144. Universidad del País Vasco, Bilbao.

West, S. E. 1969: "The Anglo-Saxon Village of West Stow: An Interim Report of the Excavations 1965-8", Medieval Archaeology, 13, pp. $1-20$.

West, S. E. 1986: West Stow: the Anglo-Saxon village. Suffolk County Planning Department, Ipswich.

Wickham, C. 2013: El legado de Roma: una historia de Europa de 400 a 1000. Pasado y Presente, Barcelona. 